2. J. Myhill, Creative sets, Z. Math. Logik Grundlagen Math. vol. 1 (1955) pp. 97-108.

3. S. Kleene, On notation for ordinal numbers, J. Symb. Logic vol. 3 (1938) pp. 150-155.

4. - Arithmetical predicates and function quantifiers, Trans. Amer. Math. Soc. vol. 79 (1955) pp. 312-340.

5. C. Spector, Recursive well orderings, J. Symb. Logic, vol. 20 (1955) pp. 151163.

6. S. Kleene, Hierarchies of number theoretic predicates, Bull. Amer. Math. Soc. vol. 61 (1955) pp. 193-213.

7. E. Zermelo, Grundlagen einer allgemeinen Theorie der mathematischen Satzsysteme, Fund. Math. vol. 25 (1935) pp. 136-146.

Massachusetts Institute of Technology

\title{
ON A SPECIAL INTEGRAL EQUATION ${ }^{1}$
}

DAVID A. WOODWARD

1. Introduction. R. H. Cameron posed the following question ${ }^{2}$ in a paper [1]. Does

$$
y(t)=x(t)+\int_{0}^{t}[x(s)]^{2} d s, \quad 0 \leqq t \leqq 1,
$$

have a solution $x \in C$ for almost every choice of $y \in C$ ? Here $C$ denotes the space of continuous functions on $0 \leqq t \leqq 1$ which vanish at $t=0$, and "almost every" means all but a set of Wiener measure ${ }^{3}$ zero. The answer is no as we proceed to show.

2. We will show that if $y \in N=\{y \in C:|y(t)+4 t|<1 / 10,0 \leqq t \leqq 1\}$ then (1.1) has no solution $x$ among the elements of $C$. Then the answer to the question is no, since $N$, a uniform neighborhood, has positive measure.

Suppose that $y \in N, x \in C$, and (1.1) holds. Let

$$
Z(t)=\left\{\begin{array}{c}
0,0 \leqq t \leqq 1 / 10 \\
-4(t-1 / 10), 1 / 10 \leqq t \leqq \pi / 4+1 / 10
\end{array}\right.
$$

Received by the editors May 26, 1958 and, in revised form, March 7, 1959.

1 This research was supported by the United States Air Force, through the Office of Scientific Research of the Air Research and Development Command, under contract No. AF 18 (603)-30.

2 This question has two other formulations found in [1].

${ }^{3}$ See, for instance [2]. 


$$
\begin{aligned}
W(t) & =\left\{\begin{array}{c}
0,0 \leqq t \leqq 1 / 10 \\
-2 \tan 2(t-1 / 10), 1 / 10 \leqq t<\pi / 4+1 / 10
\end{array}\right. \\
E & =\{t: x(t) \geqq W(t), 1 / 10 \leqq t<\pi / 4+1 / 10\}
\end{aligned}
$$

and $t_{1}=\inf E$. It is easy to see that

$$
\begin{aligned}
1 / 10 & <t_{1}<\pi / 4+1 / 10, \\
{[x(t)]^{2} } & \geqq[W(t)]^{2},
\end{aligned}
$$

and

$$
x\left(t_{1}\right)=W\left(t_{1}\right) .
$$

Since

$$
Z(t)-\frac{3}{10}>y(t), \quad \frac{1}{10} \leqq t<\frac{\pi}{4}+\frac{1}{10}
$$

and

$$
Z(t)=W(t)+\int_{0}^{t}[W(s)]^{2} d s, \quad 0 \leqq t<\pi / 4+1 / 10
$$

we have using (1.1)

$$
x(t)=y(t)-\int_{0}^{t}[x(s)]^{2} d s<Z(t)-\frac{3}{10}-\int_{0}^{t}[W(s)]^{2} d s=W(t)-\frac{3}{10}
$$

for $1 / 10 \leqq t<t_{1}$. This is a contradiction since $x\left(t_{1}\right)=W\left(t_{1}\right)$.

\section{BIBLIOGRAPHY}

1. R. H. Cameron, Nonlinear Volterra functional equations and linear parabolic differential systems, J. Analyse Math. vol. 5 (1956-1957) pp. 136-181. 258.

2. N. Wiener, Generalized harmonic analysis, Acta Math. vol. 55 (1936) pp. 117-

University of Minnesota 